\title{
Technological process of high-speed heat treatment of corrosion-resistant 36NKhTYu alloy used in production of precision elastic elements
}

\author{
Prokhorov A.V. \\ Technical engineering department \\ NArFU \\ Arkhangelsk, Russia \\ a.prohorov@narfu.ru
}

\author{
Dumanskij S.I. \\ Technical engineering department \\ NArFU \\ Arkhangelsk, Russia \\ s.dumanskij@narfu.ru
}

\author{
Dumanskij I.O. \\ Technical engineering department \\ $\mathrm{NArFU}$ \\ Arkhangelsk, Russia \\ i.dumanskij@narfu.ru
}

\begin{abstract}
We have analyzed the changing in the alloy structure during different types of heat treatment. The authors have studied the modes of high speed heat treatment with an aim to improve the technological and operational conditions of corrosion-resistant elastic elements.
\end{abstract}

Keywords - 36NKhTYu alloy, processing technology, high speed heat treatment, elastic properties, stress-related properties improvement.

\section{INTRODUCTION}

$36 \mathrm{NKhTYu}$ alloy belongs to a group of austenitic precipitation-hardening alloys of the system $\mathrm{Ni}-\mathrm{Cr}-\mathrm{Ti}-\mathrm{Al}$, its grade composition is specified by the GOST 10994-74 'Precision alloys. Grades' (chart 1). It is widely used in the industry as a material for producing critical resilient members because of a complex of its processing and operational qualities and rather economical alloying (in the group of highprecision alloys). Precisely this fact determined everincreasing attention of the metallurgists in researching the possibilities of enhancing technological processing and increase in operational corrosion resistant properties of resilient elements. Works by A.G. Rakhshtadt, V.F. Sukhovarov, O.M. Khovova investigate this alloy more thoroughly $[3,4,5,6,7]$.

TABLE I. 36NKHTYU ALLOY CHEMICAL COMPOSITION.

\begin{tabular}{|c|c|c|c|c|c|c|}
\hline \multicolumn{6}{|c|}{ Content of alloying elements, \% by mass } \\
\hline $\mathrm{C}$ & $\mathrm{Si}$ & $\mathrm{Mn}$ & $\mathrm{Cr}$ & $\mathrm{Ni}$ & $\mathrm{Ti}$ & $\mathrm{Al}$ \\
\hline \multirow{2}{*}{$<0,05$} & \multirow{2}{*}{$<0,5$} & $0,8-$ & $11,5-$ & $34,5-$ & $2,8-$ & $0,9-$ \\
& & 1,2 & 13,5 & 36,5 & 3,2 & 1,2 \\
\hline
\end{tabular}

As this alloy has a considerable amount of nickel and chrome, it has a steady austenitic structure. It is unmagnetized in the wide temperature range; in the tempered state the alloy is highly-plastic, well welded and has the increased rust resistance in the atmosphere and technical environments. The presence of the titan and aluminum, which form an austenitic intermetallic phase with nickel and iron, isomorphous matrix and have variable solubility in a $\mathrm{Fe}-\mathrm{Ni}$-Cr solid solution, leads to the considerable concreting of alloy during its aging.

\section{SPECIFICS OF 36NKHTYU ALLOY STRUCTURE FORMATION AFTER HEAT TREATMENT}

Heating of the alloy to temperatures over $950^{\circ} \mathrm{C}$ leads to formation of the uni-phase structure and is followed by the almost complete dissolution of an excess intermetallic phase. This achieves an almost extreme concentration of a solid solution. In this alloy, tempered starting with $950 \ldots 1000^{\circ} \mathrm{C}$, dispersible carbide or carbonitride fractions - carbide of chrome and carbide (carbonitride) of a titanium are found. The considerable number of these fractions settles down on highangle borders, being efficient stoppers of high-angle boundaries. Increasing the tempering temperature higher than $1000^{\circ} \mathrm{C}$ leads to some additional enrichment of a solid solution with alloying elements, such as chrome and titanium, due to dissolution of carbides and carbonitride and alignment of concentration of components of the alloy. But at the same time, the significant growth in the grain is observed.

After tempering of the alloy with the temperature of $1150^{\circ} \mathrm{C}$, due to chrome carbide dissolution, the quantity of carbide fractions in alloy sharply decreases, and after tempering at $1280^{\circ} \mathrm{C}$ a slight quantity of not expanded fractions, probably of carbides of a titanium and fraction of oxides, is observed. The concentration uniformity of the solid 
solution increases with the increase of alloy tempering temperature. However for the alloy tempered with the temperature higher than $1100^{\circ} \mathrm{C}$, some concentration stratification is observed. The compromise between growth of plasticity of the alloy because of the carbide phase dissolution and a decrease in plasticity due to an increase in the size of grain, especially at high (more than $1100^{\circ} \mathrm{C}$ ) hardening temperatures (fig. 1), is defined by the degree of concentration inhomogeneity of the alloy when heating under training.
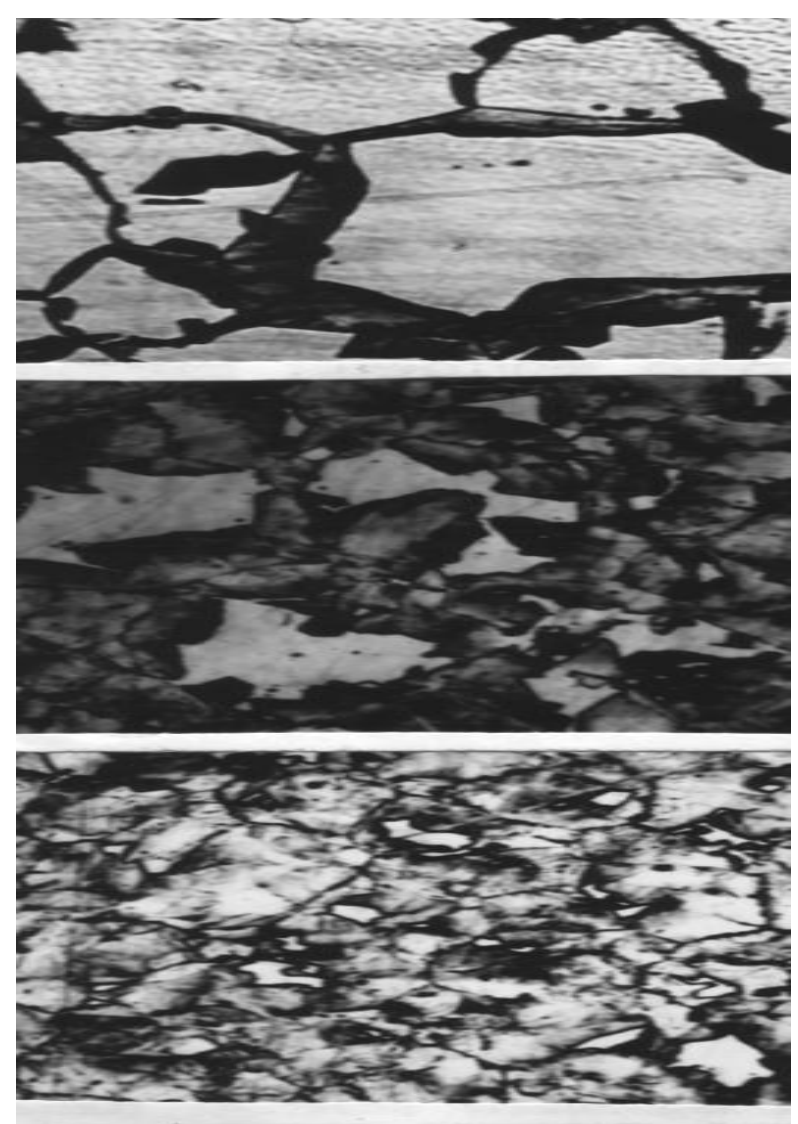

Fig. 1 The microstructure of $36 \mathrm{NKhTYu}$ alloy after usual heat treatment: quenching at $970^{\circ} \mathrm{C}$, aging at $700^{\circ} \mathrm{C}$, for 2 hours; grain sizes of hold time from top to bottom: 80 microns, 35 microns, 20 microns; ( 450 -fold increase).

When heated up to the temperatures higher than $550^{\circ} \mathrm{C}$, the tempered alloy displays a disintegration of a supersaturated solid solution. When heated up to $400^{\circ} \ldots 500^{\circ} \mathrm{C}$, the stratification of supersaturated solid solution concentration is controlled by the migration of heat balance vacancies. At the same time in the supersaturated solid solution there may be formed locally ordered areas which composition is similar to the intermetallic compounds type $(\mathrm{Ni}, \mathrm{Fe})_{3}(\mathrm{Ti}, \mathrm{Al})$, which subsequently can become $\gamma^{\prime}$-phase separation seeds.

The intensity of development of the atomic redistribution processes is substantially defined by the condition of the tempered alloy before aging. In the deformed alloy and in the alloy quenched starting with low temperatures, the stage of pre-allocation goes more intensively and fully, and this leads to the beginning of desintegration of the supersaturated solid solution.

The general continuous allocation of an excess phase is controlled by the volume diffusion in a solid solution. At the same time the $\gamma^{\prime}$-phase fractions are formed evenly in crystal grain volume. Discontinuous disintegration is connected to the migration of high-angle borders and proceeds through the grain boundary diffusion.

It has been found that the continuous disintegration has a smaller incubatory period and precedes the discontinuous disintegration. In addition, by the time of the beginning of formation of discontinuous disintegration cells in grain areas, all the alloy volume is already captured by the continuous allocation. Simultaneously with the development of reaction of discontinuous disintegration in the alloy, there is a coagulation of the equiaxed fractions which are already allocated on the continuous mechanism $\gamma^{\prime}$-phase. The process of discontinuous disintegration since the beginning of its development can be presented as the reaction of coagulation of equiaxed fractions of continuous allocation supported by local diffusion, more intensive than volume diffusion. Therefore in identical conditions of aging, rod-formed fractions in areas of discontinuous disintegration have bigger sizes of cross section than spherical ones - in areas of continuous disintegration [5, 6].

Distinctions in the mechanisms of origin and growth of fractions, $\gamma^{\prime}$-phase cause differenced in morphology and particularities of distribution of these fractions in a matrix phase and, therefore, in their interaction with dislocations, which determines the level of hardening of the aged alloy.

The condition of the alloy, when both mechanisms of interaction are manifested, corresponds to the greatest alloy hardening with the structure of continuous disintegration. The continuous disintegration structure is characterized by the dependence of the level of hardening on the aging hold time with the increase in the hardening level followed by reaching the maximum and the hardening reduction with further endurance on aging temperature.

The areas of the alloy involved in the continuous disintegration reaction are characterized by the fast reaching of the maximum hardening; there is also a weak reliance between its reached level and the aging time at the temperatures up to $750^{\circ} \mathrm{C}$. The maximum hardening in continuous disintegration zones is implemented at lower temperatures of aging and smaller hold time than in areas of the alloy with continuous allocation of the superfluous $\gamma^{\prime}$-phase. When aging alloy at the temperature of $800^{\circ} \mathrm{C}$ in the discontinuous disintegration cells, the softening begins earlier and it runs more intensively. In these aging conditions in the discontinuous disintegration cells, formation of plates of hexagonal stable $\gamma^{\prime}$-phase $\left(\mathrm{Ni}_{3} \mathrm{Ti}\right)$ takes place and it goes more intensively than in the areas of continuous allocation. Therefore this formation strengthens the matrix structure less effectively. 
The comparison of the $36 \mathrm{NKhTYu}$ alloy properties defining its operational and technical characteristics in various structural state allows defining the advantages of different alloy processing methods and the possibility of their application for the elastic elements production with a favorable complex of performance characteristics (fig. 2).

The homogenous structural condition of alloy is technologically difficult to realize, and it is still not widely applied (despite its prospects) industrially because the processing allowing one to realize the highest rates of a complex of properties of alloy with the complex structure is used for the comparison of alloy properties [5]. This processing consists in quenching the alloy in water, starting with $950^{\circ} \mathrm{C}$ after 5 minutes of hold time and aging at $700^{\circ} \mathrm{C}$ during $2 \ldots 4$ hours. Because of such processing in the alloy with an average grain size of $30 \ldots 50$ micron, about $70 \%$ of volume of alloy are captured by continuous allocation strengthening $\gamma^{\prime}$ - phases. At the same time the alloy with a hardness of $370 \ldots 400 \mathrm{HB}$ possesses high rates of durability, elasticity and plasticity:

$$
\begin{aligned}
& \sigma_{0.002}=780 \ldots 800 \mathrm{MPa} ; \sigma_{0}=1200 \ldots 1400 \mathrm{MPa} \\
& \sigma_{0.2}=850 \ldots 1100 \mathrm{MPa} ; \quad \sigma=12 \ldots 18 \% .
\end{aligned}
$$

This type of processing also provides the greatest thermal stability of the alloy reaching $300^{\circ} \mathrm{C}$. Further the described processing of the alloy is called the traditional processing.

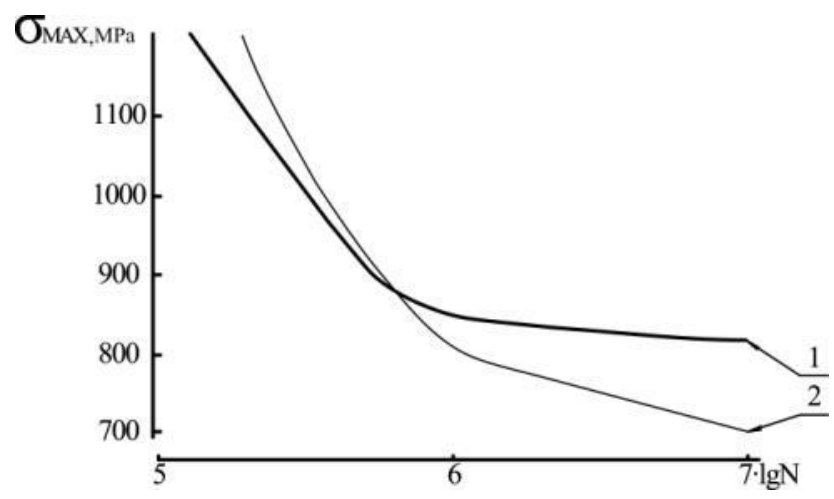

1. electroheating processing 2 . traditional processing

Fig. 2 Comparison of 36NKhTYu alloy fatigue characteristics after traditional processing and electroheating processing (probability of destruction is 50\%).

If the traditional processing is used after aging, the $36 \mathrm{NKhTYu}$ alloy has the inhomogenuous mixed structure within the grain size (fig. 1). Distinctions between the mechanism and the kinetics of alloy hardening in the areas captured by the continuous allocation or discontinuous reaction do not allow one to obtain maximum hardening in the whole alloy volume with the mixed structure in the areas captured by continuous and discontinuous disintegration at the same time. Tensions and microdeformations in the mixed structure alloy are localized mainly in the grain areas, which divide the areas with various mechanisms of supersaturated solid solution disintegration, which contributes to the decrease in the relaxation firmness of the alloy under loading; also to the emergence and distribution of fatigue cracks in the conditions of the repeated loading.

The high-speed heat treatment $[8,9,10,11]$ is deprived of these aforementioned shortcomings allowing one to divide accurately by means of a complex of preparatory the operations of the discontinuous and continuous mechanisms of the metastable strengthening phase allocation and this allows us to precisely operate the complex of all mechanical properties of the $36 \mathrm{NKhTYu}$ alloy.

\section{THE PROGRAMMED FORMATION OF THE STRUCTURE AND THE PROPERTIES OF THE 36NKHTYU ALLOY WITH HIGH-SPEED ELECTROHEATING APPLICATION DURING THE RECRYSTALLIZATION PROCESSING}

Hammer-hardening aging with relative deformation of 30 .. $70 \%$ of alloy allows one to receive a structure of full discontinuous disintegration, but the use of the hammerhardened alloy for production of irregular shape elements is limited by its low plasticity. Carrying out softening high-speed recrystallization processing of this hammer-hardened alloy allows one to receive a structure of a supersaturated solid solution with a small (up to $5 \ldots 7$ micron) grain and easily mobile high-angle borders, differing in better technological properties and the ability to disintegrate on the discontinuous mechanism when aging. Short-term (up to 30 seconds) heating to the lower temperatures of a single $\gamma^{\prime}$-phase condition of the alloy $\left(930 \ldots 950^{\circ} \mathrm{C}\right)$ allows gaining essential effect of grain fragmentation. Alloy recrystallization practically comes to an end at $930^{\circ} \mathrm{C}$ within 15 seconds, and at $970^{\circ} \mathrm{C}$ this process takes place even quicker.

Recrystallization germs form a fine-grained structure of the supersaturated $\gamma$-solid solution with an average grain size of $4 \ldots .5$ micron, irregardless of the processing temperature. An increase in hold time leads to the more intensive grain growth. At the same time increased recrystallization temperature leads to increased intensity of grain growth. The grain fragmentation, when carrying out recrystallization processing, increases with the increase of preliminary deformation. The change of relative deformation of the alloy from 50 to $80 \%$ allowed us to receive approximately a twice finer grain of the supersaturated solid solution at high-speed recrystallization processing. The maximum speeds of discontinuous reaction of superfluous $\gamma^{\prime}$-phase disengagement during discontinuous disintegration in the alloy, when using high-speed recrystallization processing, are reached when discontinuous reaction is intensified. This alloy condition can be reached through stopping the process of recrystallization of the deformed alloy at some intermediate stage as a result of its sharp cooling.

We used the effect of high-speed recrystallization processing and the subsequent aging on full discontinuous disintegration in double mechanical-heating treatment. When using this scheme, the alloy after the traditional processing is subjected to rolling with relative deformation $30 \ldots 80 \%$, after the plasticity of alloy is restored during high-speed recrystallization processing with fast heating up to $950^{\circ} \mathrm{C}$ and 
short (only several seconds) hold time at this temperature. The restored plasticity of the alloy (for example, heating at $950^{\circ} \mathrm{C}$ within 3 seconds leads to increase in relative lengthening of alloy from 5 to $20 \%$ ) allows to use this alloy in making elastic elements of irregular shape with application of a deep extract. Hardening of this alloy during low-temperature aging (600 ... $650^{\circ} \mathrm{C}$ ) is directly related to success to keep defects of a peening.

The typical microstructure of the deformed tape made from the $36 \mathrm{NKhTYu}$ alloy (degree of reduction 60\%) is presented in fig. 3. It is visible that the majority of grains along the direction of rolling are accurately elongated. Also, we can see the existence of a large number of sliding lines. The average size of grains in the alloy, which underwent rolling, is $30-50$ micron, which is typical.
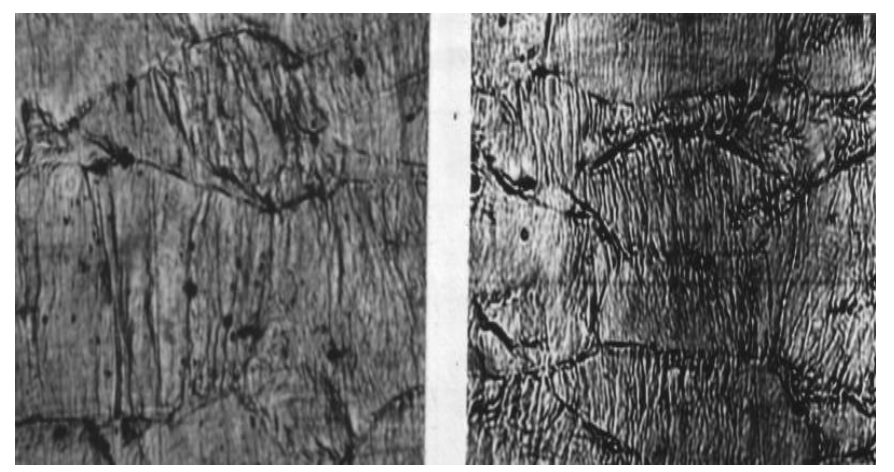

Fig. 3. 36NKhTYu alloy microstructure after tempering at $970^{\circ} \mathrm{C}$ and cold plastic deformation (rolling), degree of reduction is $60 \%$ (450-fold increase).

We have found out that when lowering the heating rate from $3000^{\circ} \mathrm{C} / \mathrm{sec}$ to $1000^{\circ} \mathrm{C} / \mathrm{sec}$, it is not possible to prevent disintegration of supersaturated solid solution of the deformed alloy during the heating. It has also been found out that the effect of alloy aging was almost identical when heating at $100^{\circ}$ and $300^{\circ} \mathrm{C} / \mathrm{sec}$.

When comparing the kinetics of change in the alloy hardness during heating up to $950^{\circ} \mathrm{C}$, it is possible to conclude that the speed of heating has an impact only at the initial stage of primary recrystallization: the aging in the course of heating leads to the delay of this stage. This influence of heating speed is weakened when increasing the temperature of processing up to $1000^{\circ} \mathrm{C}$ and even more if increasing it up to $1050^{\circ} \mathrm{C}$. Respectively even the minimum isothermal hold time, facilitating the dissolution of the allocated fractions, eliminates the distinctions in the kinetics of the recrystallization process caused by different speeds of heating. In other words, heating speed during the electric heating treatment (ET) (studied range of speeds is $3000^{\circ} \mathrm{C} / \mathrm{sec}-300^{\circ} \mathrm{C} / \mathrm{sec}$ ) does not impact the temperature and time conditions of the process completion of primary recrystallization in the deformed 36NKhTYu alloy. Influence of speed of heating reflects only the dispersion of the grains, which are formed in the conditions of electroheat treatment.

After carrying out the first stage of research, we have found out that the purposes of receiving the fine-grained recrystallized structure in all the volume of alloy are achieved (irrespective of heating speed) by electroheat treatment with heating till $1000^{\circ} \mathrm{C}(\tau=6-9 \mathrm{sec}), 1050^{\circ} \mathrm{C}(\tau=3-6 \mathrm{sec}), 1100^{\circ} \mathrm{C}$ $(\tau=3 \mathrm{sec})$. The choice of the most optimum one was determined by a complex of criteria based on detailed study of physical, mechanical and technological properties of the alloy after the specified electroheating modes.
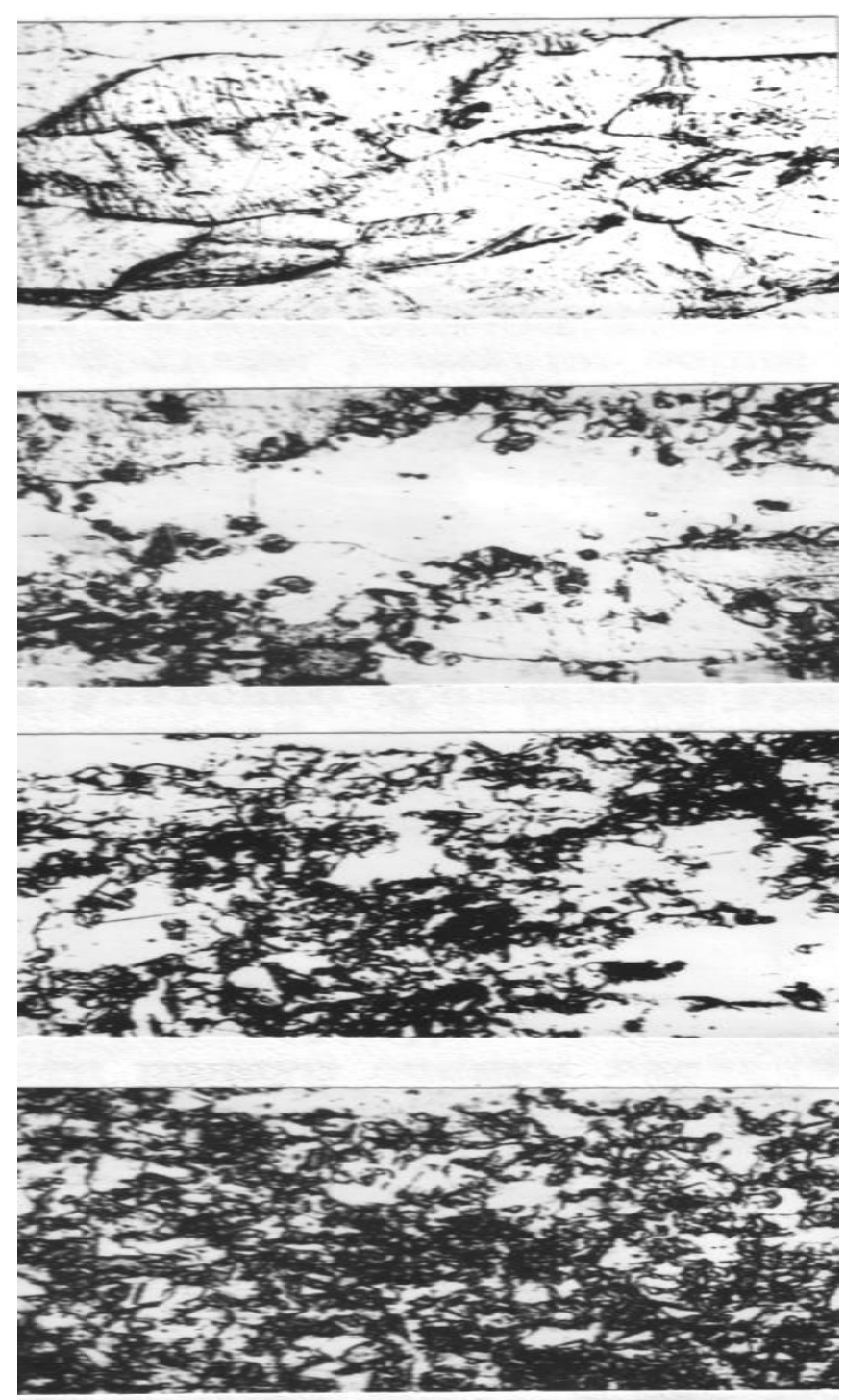

Fig. 4. 36NKhTYu alloy microstructure after deformation (degree of reduction is $60 \%$ ) and recrystallization processing at $1000^{\circ} \mathrm{C}$ (speed of heating is $3000^{\circ}$ per sec ) (450-fold increase). Hold time from top to bottom: $0 \mathrm{sec} ; 3 \mathrm{sec} ; 6$ sec; 9 sec. 


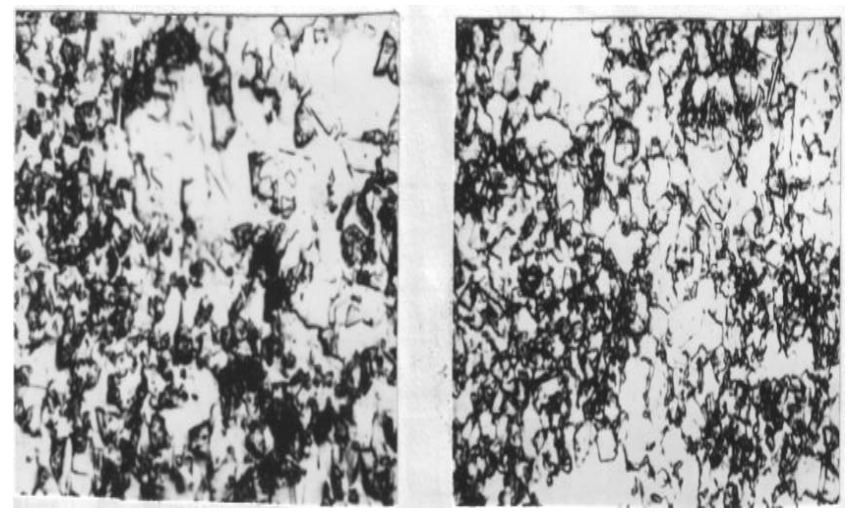

Fig. 5. 36NKhTYu alloy microstructure after deformation (degree of reduction is $60 \%$ ) and recrystallization processing at $1050{ }^{\circ} \mathrm{C}$ (speed of heating is $3000^{\circ} \mathrm{C} / \mathrm{sec}$ ) (450-fold increase). Hold time $3 \mathrm{sec} ; 6 \mathrm{sec}$.

Unlike traditional training it has to provide special structure (the grain size of 5 microns) which thanks to highmobile borders and small size of grain will provide full disintegration of solid solution when aging on the discontinuous mechanism.

Comparison of the given dependences shows that the level and the nature of strength properties and plasticity change of the alloy relates to the completeness of course of the primary recrystallization process. After the recrystallization finishes (heating modes $1000^{\circ} \mathrm{C}, \tau=9 \mathrm{sec}, 1050^{\circ} \mathrm{C}, \tau=3-6 \mathrm{sec}$ ), the alloy has the minimum of superficial characteristics which equally surpass the level of these properties of the traditionally quenched alloy (fig. 4, 5).

The recrystallization process contributes not only to the alloy softening. At the same time its ability to deformation hardening amplifies, which manifests itself in the increase in the interval between the stress limit and fluidity limit. The nature of these changes of relative lengthening of the alloy in the process of recrystallization course, which level after completion of crystallization practically corresponds to values of the traditionally quenched alloy, will be quite coordinated with these results.

Generalizing the results of the mechanical tests, it is possible to conclude the following:

a) electroheating treatment with heating up to $900^{\circ} \mathrm{C}$ does not cause development of primary recrystallization, including hold time up to $12 \mathrm{sec}$;

b) electroheating up to $1050^{\circ} \mathrm{C}(\tau=3-6 \mathrm{sec})$ or up to $1100^{\circ} \mathrm{C}(\tau=3 \mathrm{sec})$ provides the lowest level of hardening and the highest level of plasticity and the level of the specified properties of the alloy using these treatments are almost identical.

In this case the preference should be given to the processing mode which provides the best formability of the alloy. The criteria recommended for assessment of a formability of alloys were analyzed. The ratio $\sigma_{0} / \sigma_{0.2}$, which increase demonstrates improvement of a formability, concerns them first of all. By this criterion (see fig. 3.8) recrystallization processing to heating till $1050^{\circ} \mathrm{C}$ is the closest to the level of the tempered state $1050^{\circ} \mathrm{C}(\tau=6 \mathrm{c})$. The level of a formability of alloys characterizes also a ratio of the uniform and concentrated lengthening of samples: an increase in a uniform component of relative lengthening, smaller localization of sliding, smaller concentrated lengthening demonstrate improvement of a formability of the alloy. For a number of the samples, which were exposed to electroheating average relative lengthening on the increased settlement length of 60 $\mathrm{mm}$, the concentrated relative lengthening near a neck and uniform lengthening on the site remote from a neck was determined by the modes. The assessment of the alloy's structural condition after high-speed recrystallization processing in various modes carried out by means of various criteria showed that all other conditions being equal by criteria of a formability advantage has electroheating at $1050^{\circ} \mathrm{C}$ with the hold time of $6 \mathrm{sec}$. At the same time, the priority should be given to the lower heating speed.

The offered structural test also gives the grounds to draw certain conclusions concerning the size of the average size of grains of such area along with the conclusion about the most optimum mode of high-speed recrystallization processing. According to the available data [1] the applied control aging $600^{\circ} \mathrm{C}, 2$ hours guarantees the development of full discontinuous disintegration in $36 \mathrm{NKhTYu}$ alloy with an average grain diameter of 1 micron. In this case, even after the best electric heating treatment ode $\left(1050^{\circ} \mathrm{C}, 6 \mathrm{sec}\right.$, heating speed $300^{\circ} \mathrm{C} / \mathrm{sec}$ ) and aging at $600^{\circ} \mathrm{C} / 2$ hours the small grain areas corresponding to continuous allocation of the strengthening phase are nevertheless present in the structure of alloy. Therefore, the aforementioned assessment of the average size of the recrystallized grains after electric heating treatment with heating at $1050^{\circ} \mathrm{C}, \tau=6 \mathrm{sec}$ (heating speed. $300^{\circ} \mathrm{C} / \mathrm{sec}$ ) $-3-5$ micron is quite fair.

The conducted research has shown that high-speed recrystallization processing with heating up to $1050^{\circ} \mathrm{C}$ (heating speed. $300^{\circ} \mathrm{C} / \mathrm{sec}$ ) meets the qualifying standards which consider a possibility of getting oversaturated solid solution with a specific fine-grained (5 microns) recrystallized structure at an appropriate level of technological plasticity of the alloy mostly by a complex of criteria

The process of primary recrystallization in the conditions of this type of heating provides formation of the required structure and is close to completion at hold time of $3 \mathrm{sec} / \mathrm{It}$ is important to mention that the increase in hold time up to $6 \mathrm{sec}$ does not cause considerable changes in the structure and in the alloy properties (fig. 6, 7). This fact can serve as an indicator of sufficient technological effectiveness of the recommended mode of recrystallization processing. 

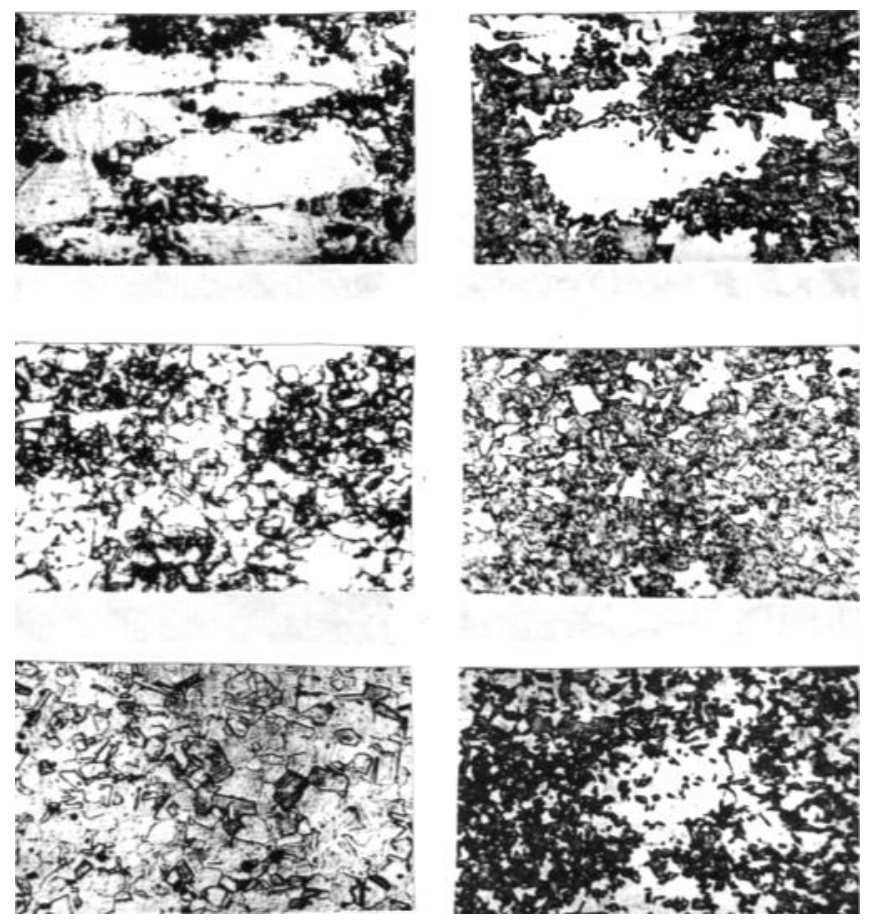

Fig. 6. 36NKhTYu alloy microstructure after high-speed recrystallization processing (first column) and controlled aging at $600^{\circ} \mathrm{C}$, for 2 hours (second column). Recrystallization processing (heating speed is $3000^{\circ} \mathrm{C} / \mathrm{sec}$ ): first row - $1000^{\circ} \mathrm{C}$, endurance $-3 \mathrm{sec}$; second row $-1100^{\circ} \mathrm{C}$, endurance - $9 \mathrm{sec}$; third row $-1000^{\circ} \mathrm{C}$, hold time - 9 sec.
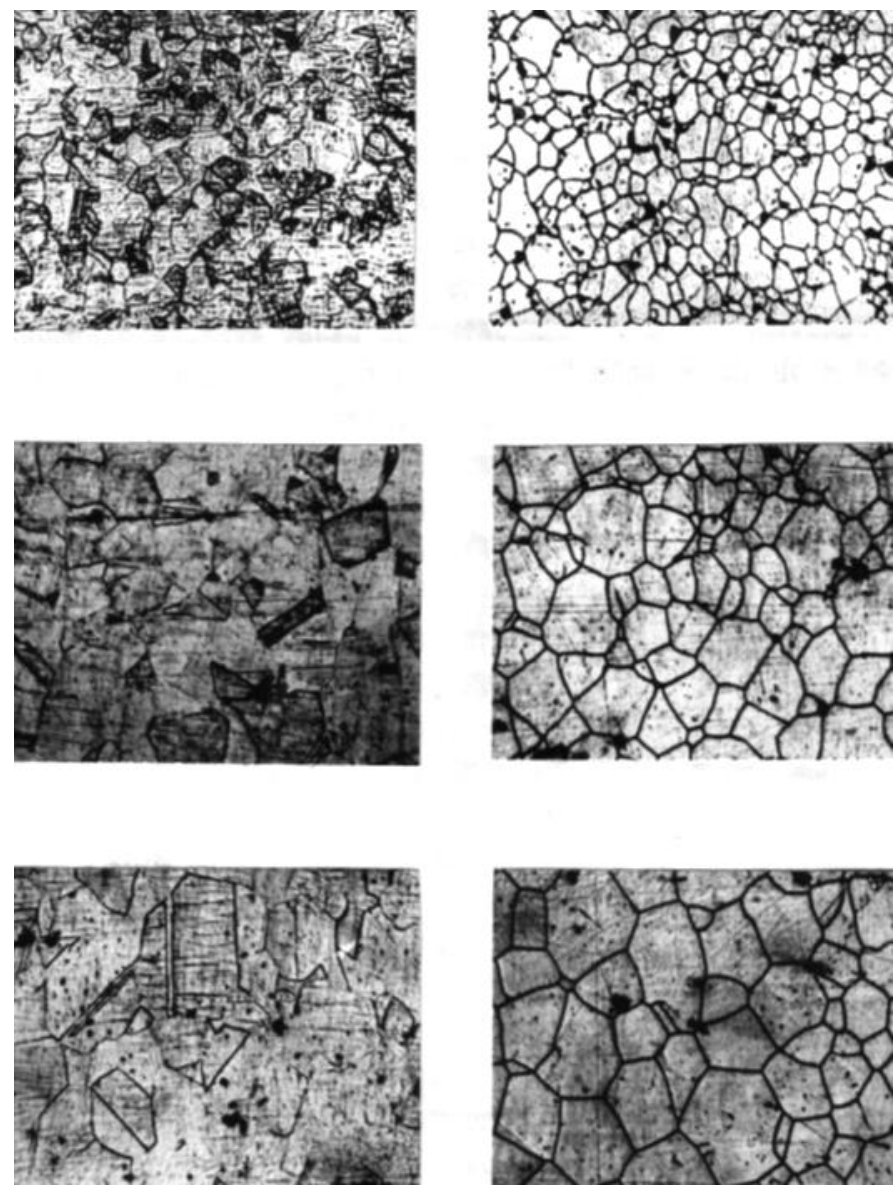

Fig. 7. The alloy $36 \mathrm{NKhTYu}$ microstructure after high-speed recrystallization processing at the temperature of $1250^{\circ} \mathrm{C}$ (first column) and final aging at 600 ${ }^{\circ} \mathrm{C}$, for $2 \mathrm{~h}$ (second column). Recrystallization processing hold time (heating speed is $3000^{\circ} \mathrm{C} / \mathrm{sec}$ ): first row - $0 \mathrm{sec}$; second row - $2 \mathrm{sec}$; third row - $5 \mathrm{sec}$.

\section{CONCLUSION}

1. We have found the optimum mode of carrying out the electroheating with return processing: heating up to $1000^{\circ} \mathrm{C}$, hold time of 3-6 sec, heating speed of $300-3000^{\circ} \mathrm{C} / \mathrm{sec}$, the accelerated cooling which guarantees formation in the alloy subjected to preliminary aging at $680^{\circ} \mathrm{C}, \tau=6 \mathrm{~h}$, a special structure of supersaturated disintegration in the whole alloy volume at the final aging.

2. The authors developed the technology of strengthening the $36 \mathrm{NKhTYu}$ alloy mechanical-heat treatment: $50 \%$ deformation, preliminary aging at $680^{\circ} \mathrm{C}, \tau=6 \mathrm{~h}$, electroheating by the passing current ( $\mathrm{V}$ heat. $\left.300-3000^{\circ} \mathrm{C} / \mathrm{sec}\right)$ at $1000^{\circ} \mathrm{C}$, hold time of 3-6 sec, cooling between the water-cooling plates, aging at $600^{\circ} \mathrm{C}, \tau=2 \mathrm{~h}$. Its application provides the realization of the elastic limit at $\sigma_{0.005}=1280 \mathrm{MPa}, \sigma_{0.002}=1120 \mathrm{MPa}$, and the conditional endurance limit at $\sigma_{10^{7}}^{R}=960 \mathrm{MPa}$, which exceed the levels by $40 \%$ when carrying out traditional heat treatment.

3. It was shown that in the conditions of the identical finegrained structure with the uniform continuous allocation strengthening of the $\gamma^{\prime}$-phase in the whole $36 \mathrm{NKhTYu}$ alloy volume, the most disperse lamellar structure (which is formed 
at the lowered temperature of final aging $-600^{\circ} \mathrm{C}$ ) provides the higher resistance to fatigue failure.

4. The lowest level of hardening and the highest level of plasticity (for the effective stamping) are provided by the electroheating to $1050^{\circ} \mathrm{C}(\tau=3-6 \mathrm{sec})$ or to $1100^{\circ} \mathrm{C}(\tau=3 \mathrm{sec})$, and the levels of the alloy specified properties after these modes are almost identical.

5. The research showed that the technological processes, using recrystallization processing of the $36 \mathrm{NKhTYu}$ alloy with the high-speed electrocontact heating application, are a promising and highly effective way of significant improvement of technological and operational properties of the corrosion-resistant elastic elements.

\section{References}

[1] V.F. Sukhovarov, R. P. Ivanova, V.V. Karavayeva, R. D. Strokatov. "Thermo-mechanical Alloy Processing Aging", Physics of Metals and Metallurgical Science, Vol. 6, pp.1268 - 1272, 1975.

[2] A.G. Rakhshtadt, Spring Steels and Alloys, Metallurgiya, Moscow, 1982, $400 \mathrm{p}$

[3] A.G. Rakhshtadt, O.M. Khovova, A.V. Khan, Research of Intensification of Faltering Disintegration Process In The Age-
Hardening Austenitic Alloy 36NKhTYu, Diffusion; phase transformations, mechanical properties of metals and alloys, VZMI, Moscow, pp. $28-39,1980$.

[4] A.G. Rakhshtadt and O.M. Khovova, Effect of the mechanism of segregation of -phase on the properties of nonmagnetic precipitationhardening spring alloy $36 \mathrm{NKhTYu}$ at room and elevated temperatures," in Structure and Physicomechanical Properties of Nonmagnetic Steels, Nauka, pp. $78-82,1986$.

[5] V.F. Sukhovarov, R.D. Strokatov, "Ultrafine Grain acquisition In Alloy 36NKhTYu aging using discontinuous release", Physics of metals and metallurgical science, vol.44, №1, pp. 195 - 198, 1977.

[6] O.M. Khovova "A study of Discontinuous Allocation of the $\gamma^{\prime}$-phase And Its Influence On the Properties of Spring Alloy 36NkhTYu," Works MVTU of N. E. Bauman, Vol. 403, pp.61-70, 1983.

[7] O.M. Khovova, A.G. Rakhshtadt, New processes of alloy aging. Machinostroyenie, Moscow, 1988.

[8] I.N. Kidin, Basic Physics of metals and alloys Electroheat Treatment, Metallurgiya, Moscow, 1969.

[9] M.N. Bodyako, S. A. Astapchik, Electroheat Treatment of Alloys With Special Properties, Naukova Dumka, Kiev, 1977.

[10] P.I. Polukhin, S.S. Gorelik, V.K. Vorontsov, Basic Physics of Plastic Deformation, Metallurgiya, Moscow, 1982.

[11] V.V. Gridnev, A.I. Yefimov, A.L. Sozinov, Recrystallization of the Disperse Hardening Alloys Features During High-Speed Continuous Electroheating, Nickel-Based Heat Resisting and Heat-resistant Steels and Alloys, Nauka, Moscow, pp. 150-153, 1984. 